\title{
Forty Nine
}

National Cancer Institute

\section{Source}

National Cancer Institute. Forty Nine. NCI Thesaurus. Code C105796.

A natural number greater than forty-eight and less than fifty and the quantity that it denotes. 